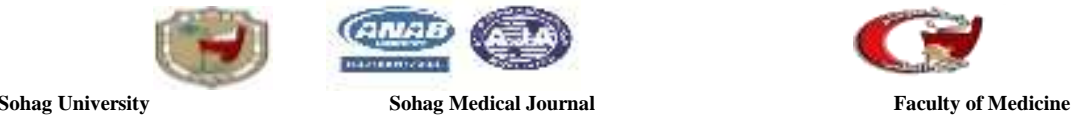

\title{
Direct Markers of Liver Fibrosis
}

\author{
Amira Maher ${ }^{1}$, Ghada M Galal ${ }^{1}$, Nagwa Sayed Ahmed ${ }^{2}$, El- \\ Zahraa Mohammed Meghezel $^{1}$ \\ Department of Tropical Medicine and Gastroenterology ${ }^{1}$, Medical \\ Biochemistry ${ }^{2}$, \\ Sohag Faculty of Medicine, Sohag University.
}

\begin{abstract}
Liver fibrosis is a chronic condition that originates as a result of prolonged hepatic injury. Liver fibrosis is caused mainly by Schistosomiasis, chronic hepatitis $\mathrm{C}$ and B viral infections, non-alcoholic fatty liver disease, alcoholic liver disease, cholestatic and autoimmune liver diseases. Hepatic stellate cells are the master cells in the fibrosis process regardless of the cause. HSCs activation involves two separate stages: the initiation stage and the perpetuation stage. The activated HSCs up-regulate gene expression of extracellular matrix elements, matrix-degrading enzymes, and their inhibitors. The components of fibrotic ECM or inflammatory mediators implicated in either the process of fibrosis or degradation of scar tissue could be used as direct markers of fibrosis. Direct indices of fibrosis are classified into direct markers associated with matrix deposition such as HA and laminin, direct markers associated with matrix degradation such as MMPs and TIMPs, and Cytokines and chemokines linked to hepatic fibrosis such as TGF- $\beta 1$ and PDGF. The validation of these markers for use in clinical practice instead of liver biopsy should be balanced against the possibility of misleading results of these markers as they are affected by factors other than fibrosis.
\end{abstract}

\section{Keywords: Liver fibrosis, hepatic stellate cell, direct markers of fibrosis} Abbreviations

ALD: alcoholic liver disease, CHB: chronic hepatitis B, CHC: chronic hepatitis C, ECM: extracellular matrix, ET: endothelin, HA: hyaluronic acid, HBV: hepatitis B virus, HCV: hepatitis C virus, HSCs: Hepatic stellate cells, KC: Kupffer cells, MCP: monocyte chemoattractant protein, MMP: matrix metalloproteinase, NAFLD: nonalcoholic fatty liver disease, NASH: non-alcoholic steatohepatitis, PIIINP: procollagen type III amino-terminal peptide, PCIP: Procollagen type I carboxyterminal peptide, PDGF: platelet-derived growth factor, ROC: receiver operator curve, ROS: reactive oxygen species, TGF $\beta 1$ : transforming growth factor-beta 1, WBC: white blood cell.

\section{Introduction}

Hepatic fibrosis is a chronic process that originates as a result of prolonged hepatic injury. The process of liver fibrosis involves remodeling of hepatic parenchyma with gradual deposition of extracellular matrix 
SOHAG MEDICAL JOURNAL

(ECM) and hepatic parenchyma nodular regeneration. When left without treatment, hepatic fibrosis progresses into cirrhosis resulting in progressive liver cell failure ${ }^{[1]}$.

\section{Etiology}

Liver fibrosis is caused mainly by Schistosomiasis, chronic hepatitis $\mathrm{C}$ (HCV) and $\mathrm{B}(\mathrm{HBV})$ viral infections, non-alcoholic fatty liver disease (NAFLD), alcoholic liver disease (ALD), cholestatic and autoimmune liver diseases ${ }^{[2]}$ in addition to other uncommon-diseases like

Hemochromatosis and Wilson's disease [3].

\section{Pathogenesis}

Hepatic stellate cells (HSCs) are the master cells in the fibrosis process regardless of the cause ${ }^{[4]}$. The process of fibrosis involves the activation of quiescent HSCs to myofibroblast-like cells ${ }^{[5]}$.

HSCs' activation involves two separate stages. The first stage, which is the "initiation phase", involves the initial modifications of HSCs to myofibroblast-like cells to be more reactive with proliferative and fibrogenic cytokines. HSCs' activation is initiated via signals derived from Apoptotic bodies resulting from injured hepatocytes, reactive oxygen species (ROS), and acetaldehyde and lipid peroxidation products. The hepatocyte-apoptotic bodies are phagocytosed by Kupffer cells (KCs). KCs, platelets, polymorph nuclear leucocytes and infiltrating immune cells in addition to sinusoidal endothelium and cholangiocytes produce mediators such as ROS, tumor necrosis factor $\alpha$, platelet-derived growth factor (PDGF), interleukin-1 $\beta$, endothelial growth factor, transforming growth factor-beta 1 (TGF $\beta 1$ ) that stimulates HSCs' activation and proliferation ${ }^{[6]}$.

The second stage of HSCs activation (the "perpetuation phase") includes the following changes: survival, migration, proliferation, fibrogenesis. The activated phenotype persists with the persistence of the injurious factor. HSCs' chemotaxis, migration, and proliferation are stimulated by PDGF and the abnormal ECM ${ }^{[6]}$. The process of HSCs' activation is summarized in figure 1 .

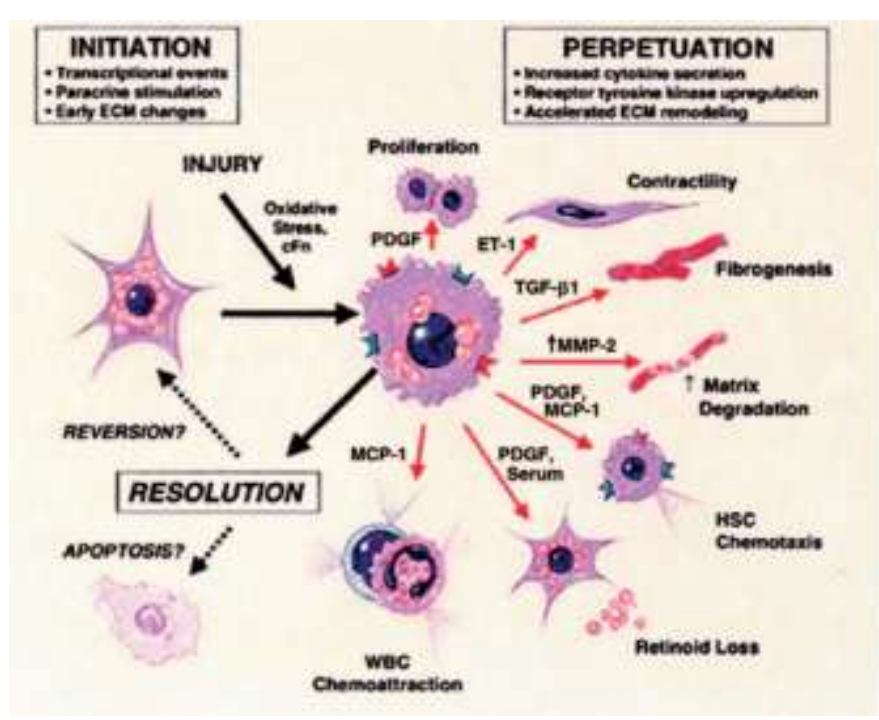


Figure 1: The process of HSCs' activation (Adapted from Hepatic Stellate Cells and Liver Fibrosis) ${ }^{[5]}$.

PDGF: platelet-derived growth factor, ET: endothelin, TGF- $\beta 1$ : transforming growth factor beta1, MMP: matrix metalloproteinase, MCP: monocyte chemoattractant protein, WBC: white blood cell.

ECM remodeling and accumulation occurs as a result of up-regulation of gene expression of ECM elements, matrix-degrading enzymes and their inhibitors by the activated HSCs ${ }^{[5]}$.

The fibrotic ECM contains high amounts of type I collagen ${ }^{[7]}$, matrix glycoproteins such as fibronectin, laminin, and hyaluronic acid ${ }^{[8]}$. The deposition of ECM results from excessive production and decreased degradation of fibrous tissue. In the case of liver damage, the activity of matrix metalloproteinases (MMPs), which are the most potent stimulators of ECM degradation, is suppressed due to the increased production of tissue inhibitors of metalloproteinases (TIMPs) ${ }^{[9]}$.

The components of fibrotic ECM or inflammatory mediators implicated in either the process of fibrosis or degradation of scar tissue could be used as direct markers of fibrosis ${ }^{[9]}$. These markers are categorized into 1) Direct markers associated with matrix deposition. 2) Direct markers associated with matrix degradation. 3) Cytokines and chemokines associated with hepatic fibrosis ${ }^{[10]}$.

1. Direct markers associated with matrix deposition:

- Hyaluronic acid:

Hyaluronic acid (HA) was frequently evaluated in chronic hepatitis $\mathrm{C}$ (CHC) and NAFLD. It was less frequently evaluated in ALD and chronic hepatitis B (CHB) infection ${ }^{[10]}$. HA is a valuable test in predicting severe fibrosis [11]. Sakugawa et al ${ }^{[12]}$ proposed a cutoff value of $\geq 50 \mathrm{ng} / \mathrm{mL}$ for predicting advanced fibrosis. It has a negative predictive value of 98-100 percent for cirrhosis ${ }^{[13]}$. HA level decreases in $\mathrm{CHC}$ patients who are responders to antiviral therapy ${ }^{[14]}$.

\section{- Laminin:}

Laminin is a noncollagenous glycoprotein that is deposited in the hepatic basement membrane by HSCs [15]. It can predict significant fibrosis in $\mathrm{CHC}$ cases with 77 percent accuracy ${ }^{[16]}$.

- Procollagen type I carboxy-terminal peptide and procollagen type III amino-terminal peptide:

The Procollagen type I carboxy-terminal peptide (PCICP) is an essential element of the connective tissue $^{[15]}$. Its upper limit of normal is $202 \mu \mathrm{g}$ in males and $170 \mu \mathrm{g}$ in females, and this level increases in cases with moderate to severe liver disease ${ }^{[10]}$.

The procollagen type III aminoterminal peptide (PIIINP) is also an essential element of connective tissue. PIIINP serum values show a correlation with serum bilirubin values in cirrhotic patients. Its upper limit of normal is $0.8 \mathrm{U} / \mathrm{mL}^{[17]}$. In CHC and ALD patients, PIIINP levels increase in patients with more severe liver disease. Moreover, its level decreases in $\mathrm{CHC}$ patients who respond to interferon therapy. Furthermore, Serum values of PIIINP are high in cases with autoimmune liver disease and these levels decrease in responders to immunosuppressive therapy ${ }^{[10]}$.

\section{- Type IV collagen:}

Type IV collagen is an element of ECM with three various areas: an amino-terminal domain (7S domain), a central helix domain, and a carboxyterminal domain ${ }^{[10]}$. Type IV collagen $7 \mathrm{~S}$ domain is considered a direct marker to detect non-alcoholic 
steatohepatitis (NASH) and to evaluate the severity of fibrosis in these patients. It has a cutoff value of $\geq 5 \mathrm{ng} / \mathrm{mL}$ for predicting NASH and advanced fibrosis ${ }^{[18]}$.

\section{- YXL-40 chondrex:}

YXL-40 chondrex is a part of the chitinase family. It has a role in ECM remodeling and degradation ${ }^{[19]}$. Serum values of more than $330 \mu \mathrm{g} / \mathrm{L}$ are associated with severe fibrosis in various etiologies of liver injury ${ }^{[20]}$.

2. Direct markers associated with matrix degradation:

- MMPs: They have a major role in EMC degradation. MMPs have three forms in humans ${ }^{[21]}$ :

a. MMP-1 (collagenases):

Its levels correlate inversely with necrosis and fibrosis. On the other hand, MMP-1/TIMP-1 (tissue inhibitors of matrix metalloproteinases) complex values increase with more severe inflammation, but they have no correlation with the stage of liver fibrosis ${ }^{[10]}$.

b. MMP-2 (gelatinase-A):

MMP-2 is produced by HSCs in diseased liver ${ }^{[10]}$. In CHC, MMP-2 can predict cirrhosis with an accuracy of $92 \%$. The cutoff value in cirrhosis is 2.4 fold higher than the value in controls ${ }^{[22]}$. Levels higher than 0.550 are associated with severe fibrosis ${ }^{[23]}$.

c. MMP-9 (gelatinase-B):

MMP-9 is secreted by KCs in the liver ${ }^{[10]}$. MMP-9 was proposed to have a diagnostic role in hepatocellular carcinoma ${ }^{[24]}$. MMP-9 has a negative correlation with histological disease in chronic hepatitis, as cirrhotic patients have the lowest serum values ${ }^{[25]}$.

- $\quad$ TIMPs (TIMP-1, TIMP-2):

TIMPs are linked to the degradation of collagen ${ }^{[26]}$. They modify the activation and function of MMPs. The serum value of TIMPs increases with increasing stage of fibrosis ${ }^{[25]}$.

3. Cytokines and chemokines associated with hepatic fibrosis:

- TGF- $\beta$ 1:

TGF- $\beta 1$ is the most potent stimulus for ECM deposition. It has high serum values in the setting of $\mathrm{HCV}$ infection and these values increase with increasing stage of fibrosis ${ }^{[27]}$.

- PDGF:

PDGF is a major stimulus for HSCs' mitosis in vitro. The level of PDGF increases with increasing stage of fibrosis ${ }^{[28]}$.

Among the above-mentioned markers, $\mathrm{HA}$ has the best validation for use in clinical practice ${ }^{[29]}$ and a negative score could be used to preclude fibrosis [30]. HA was extensively evaluated in various forms of liver diseases. The Serum level of HA was found to be correlated with the stage of fibrosis in CHC patients ${ }^{[31-32]}$, both HBeAg positive [33] and negative [34] patients, NAFLD [35], and PBC ${ }^{[36]}$. Moreover, HA values were raised in ALD patients ${ }^{[37]}$ and high serum HA was a predictor of cirrhosis in these cases ${ }^{[38]}$.

\section{Clinical utility of direct markers of fibrosis}

Liver biopsy has many limitations as it is an invasive painful costly maneuver that carries the risk of life-threatening complications such as intra-peritoneal hemorrhage and hemobilia [39-40]. Inter-observer variability ${ }^{[41]}$ and sampling error also may occur ${ }^{[42]}$.

On the other hand, the accuracy of non-invasive markers for evaluation of fibrosis is still unproven. These markers lack specificity to the liver. Moreover, their serum levels are affected by inflammation not only by fibrosis ${ }^{[43]}$. Furthermore, most of these indices are validated in $\mathrm{HCV}$ patients and further research is 
required to validate its use in $\mathrm{HBV}$, ALD and other causes of chronic liver diseases ${ }^{[44]}$.

So, in clinical practice, non-invasive markers of fibrosis cannot completely replace liver biopsy ${ }^{[45]}$, and biopsy is still a must in many cases when the values of indirect markers are inconclusive ${ }^{[46]}$.

\section{Conclusion:}

Liver fibrosis is a chronic condition that originates as a result of prolonged hepatic injury. HSCs have the main role in liver fibrosis regardless of the cause. HSCs activation involves two separate stages; the" initiation phase" and the "perpetuation phase". ECM remodeling and accumulation occurs as a result of up-regulation of gene expression of ECM elements, matrixdegrading enzymes and their inhibitors by the activated HSCs. The components of fibrotic ECM, or inflammatory mediators implicated in either the process of fibrosis or degradation of scar tissue could be used as direct markers of fibrosis which are classified into: Direct markers associated with matrix deposition such as HA and laminin, direct markers associated with matrix degradation such as MMPs and TIMPs, and Cytokines and chemokines linked to hepatic fibrosis such as TGF- $\beta 1$ and PDGF. Among these markers, HA has the best validation for use in clinical practice. However, the clinical validation of these markers for use in clinical practice instead of liver biopsy is still a question. Indirect markers can overcome the invasiveness and other limitations of biopsy. However, this should be balanced against the possibility of misleading results of these markers as they are affected by factors other than fibrosis.

\section{References}

1. Pinzani M. Pathophysiology of liver fibrosis. Digestive Diseases 2015;33(4):492-7.

2. R, Tacke F. Liver fibrosis: from pathogenesis to novel therapies. Digestive Diseases 2016;34(4):410-22.

3. Higashi T, Friedman SL, Hoshida Y. Hepatic stellate cells as key target in liver fibrosis. Advanced Drug Delivery Reviews 2017;121:27-42.

4. Bridle KR, Crawford DH, Ramm GA. Identification and characterization of the hepatic stellate cell transferrin receptor. The American Journal of Pathology 2003;162(5):1661-7.

5. Moreira RK. Hepatic stellate cells and liver fibrosis. Archives of Pathology \& Laboratory Medicine 2007;131(11):1728-34.

6. Gandhi CR. Hepatic stellate cell activation and pro-fibrogenic signals. Journal of Hepatology 2017;67(5):1104-5.

7. Gressner A, Weiskirchen R. Modern pathogenetic concepts of liver fibrosis suggest stellate cells and TGF- $\beta$ as major players and therapeutic targets. Journal of Cellular and Molecular Medicine 2006;10(1):76-99.

8. Bataller R, Brenner DA. Liver fibrosis. The Journal of Clinical Investigation 2005;115(2):209-18.

9. Bansal MB, Friedman SL. Hepatic Fibrogenesis. In: Sherlock's Diseases of the Liver and Biliary System. Dooley JS, Lok AS, Garcia-Tsao G, Pinzani M. (Eds.). Thirteens edition. John Wiley \& Sons; 2018. 6:82-92. 
10. Fallatah HI. Noninvasive biomarkers of liver fibrosis: an overview. Advances in Hepatology 2014;2014.

11. Vizzutti F, Arena U, Nobili V, Tarquini R, Trappoliere M, Laffi G, et al. Non-invasive assessment of fibrosis in non-alcoholic fatty liver disease (NAFLD). Annals of Hepatology 2009;8(2):89-94.

12. Sakugawa H, Nakayoshi $\mathrm{T}$, Kobashigawa K, Yamashiro T, Maeshiro T, Miyagi S, et al. Clinical usefulness of biochemical markers of liver fibrosis in patients with nonalcoholic fatty liver disease. World Journal of Gastroenterology 2005;11(2):255-9.

13. Bourliere M, Penaranda G, Ouzan D, Renou C, Botta-Fridlund D, Tran A, et al. Optimized stepwise combination algorithms of noninvasive liver fibrosis scores including Hepascore in hepatitis C virus patients. Alimentary Pharmacology \& Therapeutics 2008;28(4):458-67.

14. Walsh KM, Fletcher A, MacSween RN, Morris AJ. Basement membrane peptides as markers of liver disease in chronic hepatitis C. Journal of Hepatology 2000;32(2):325-30.

15. Baranova A, Lal $\mathrm{P}$, Birerdinc A, Younossi ZM. Non-invasive markers for hepatic fibrosis. BMC Gastroenterology 2011;11(1):91.

16. Sebastiani G. Non-invasive assessment of liver fibrosis in chronic liver diseases: implementation in clinical practice and decisional algorithms. World Journal of Gastroenterology 2009;15(18):2190203.
17. Gallorini A, Plebani $M$, Pontisso $P$, Chemello L, Masiero M, Mantovani $\mathrm{G}$, et al. Serum markers of hepatic fibrogenesis in chronic hepatitis type $\mathrm{C}$ treated with alfa-2A interferon. Liver 1994;14(5):257-64.

18. Yoneda $M$, Mawatari $H$, Fujita $K$, Yonemitsu K, Kato S, Takahashi H, et al. Type IV collagen $7 \mathrm{~s}$ domain is an independent clinical marker of the severity of fibrosis in patients with nonalcoholic steatohepatitis before the cirrhotic stage. Journal of Gastroenterology 2007;42(5):375-81.

19. Johansen JS, Christoffersen P, Møller S, Price PA, Henriksen JH, Garbarsch $\mathrm{C}$, et al. Serum YKL-40 is increased in patients with hepatic fibrosis. Journal of Hepatology 2000;32(6):911-20.

20. Saitou Y, Shiraki K, Yamanaka Y, Yamaguchi Y, Kawakita T, Yamamoto $\mathrm{N}$, et al. Noninvasive estimation of liver fibrosis and response to interferon therapy by a serum fibrogenesis marker, YKL-40, in patients with $\mathrm{HCV}$-associated liver disease. World Journal of Gastroenterology 2005;11(4):476.

21. Sun J. Matrix metalloproteinases and tissue inhibitor of metalloproteinases are essential for the inflammatory response in cancer cells. Journal of Signal Transduction 2010;2010.

22. Boeker $\mathrm{KH}$, Haberkorn CI, Michels D, Flemming P, Manns MP, Lichtinghagen R. Diagnostic potential of circulating TIMP-1 and MMP-2 as markers of liver fibrosis in patients with chronic hepatitis C. Clinica Chimica Acta 2002;316(1-2):71-81.

23. Murawaki Y, Ikuta Y, Okamoto K, Koda M, Kawasaki H. Diagnostic value of serum markers of connective tissue turnover for predicting 
histological staging and grading in patients with chronic hepatitis C. Journal of Gastroenterology 2001;36(6):399-406.

24. Hayasaka A, Suzuki N, Fujimoto N, Iwama S, Fukuyama E, Kanda Y, et al. Elevated plasma levels of matrix metalloproteinase-9 (92-kd type IV collagenase/gelatinase B) in hepatocellular carcinoma. Hepatology 1996;24(5):1058-62.

25. Badra G, Lotfy M, El-Refaie A, Obada M, Abdelmonem E, Kandeel S, et al. Significance of serum matrix metalloproteinase- 9 and tissue inhibitor of metalloproteinase-1 in chronic hepatitis $\mathrm{C}$ patients. Acta Microbiologica et Immunologica Hungarica 2010;57(1):29-42.

26. Curry MP, Nezam A. Noninvasive assessment of hepatic fibrosis: Overview of serologic and radiographic tests. UpToDate, Waltham, MA: Walters Kluwer Health 2016.

27. Kanzler S, Baumann M, Schirmacher P, Dries V, Bayer E, Gerken G, et al. Prediction of progressive liver fibrosis in hepatitis $\mathrm{C}$ infection by serum and tissue levels of transforming growth factor- $\beta$. Journal of Viral Hepatitis 2001;8(6):430-7.

28. Zhang BB, Cai WM, Weng HL, Hu ZR, Lu J, Zheng M, et al. Diagnostic value of platelet derived growth factor-BB, transforming growth factor$\beta 1$, matrix metalloproteinase- 1 , and tissue inhibitor of matrix metalloproteinase-1 in serum and peripheral blood mononuclear cells for hepatic fibrosis. World Journal of Gastroenterology 2003;9(11):2490-6.

29. Lee HH, Seo YS ،Um SH, Won NH, Yoo H, Jung ES, et al. Usefulness of non-invasive markers for predicting significant fibrosis in patients with chronic liver disease. Journal of
Korean
Medical
Science
2010;25(1):67-74.

30. Almpanis Z, Demonakou M, Tiniakos D. Evaluation of liver fibrosis:"Something old, something new...". Annals of Gastroenterology: Quarterly Publication of the Hellenic Society of Gastroenterology 2016;29(4):445-53.

31. Matsue $Y$, Tsutsumi $M$, Hayashi $N$, Saito T, Tsuchishima M, Toshikuni N, et al. Serum osteopontin predicts degree of hepatic fibrosis and serves as a biomarker in patients with hepatitis $\mathrm{C}$ virus infection. PloS One 2015;10(3): 0118744.

32. Fontana RJ, Goodman ZD, Dienstag JL, Bonkovsky HL, Naishadham D, Sterling RK, et al. Relationship of serum fibrosis markers with liver fibrosis stage and collagen content in patients with advanced chronic hepatitis C. Hepatology 2008;47(3):789-98.

33. Zeng MD, Lu LG, Mao YM, Qiu DK, Li JQ, Wan MB, et al. Prediction of significant fibrosis in $\mathrm{HBeAg}$ positive patients with chronic hepatitis B by a noninvasive model. Hepatology 2005;42(6):1437-45.

34. Montazeri G, Estakhri A, Mohamadnejad M, Nouri N, Montazeri F, Mohammadkani A, et al. Serum hyaluronate as a non-invasive marker of hepatic fibrosis and inflammation in $\mathrm{HBeAg}$-negative chronic hepatitis B. BMC Gastroenterology 2005;5(1):32.

35. Chwist A, Hartleb M, Lekstan A, Kukla M, Gutkowski K, Kajor M. A composite model including visfatin, tissue polypeptide-specific antigen, hyaluronic acid, and hematological variables for the diagnosis of moderate-to-severe fibrosis in nonalcoholic fatty liver disease: a 
preliminary study. Pol Arch Med Wewn 2014;124(12):704-12.

36. Guéchot J, Poupon RE, Giral P, Balkau B, Giboudeau J, Poupon R. Relationship between procollagen III aminoterminal propeptide and hyaluronan serum levels and histological fibrosis in primary biliary cirrhosis and chronic viral hepatitis C. Journalof Hepatology1994;20(3):38893.

37. Sowa JP, Atmaca Ö 'Kahraman A, Schlattjan M, Lindner M, Sydor S, et al. Non-invasive separation of alcoholic and non-alcoholic liver disease with predictive modeling. PLoS One 2014;9(7):e101444.

38. Stickel F, Poeschl G, Schuppan D, Conradt C, Strenge-Hesse A, Fuchs FS, et al. Serum hyaluronate correlates with histological progression in alcoholic liver disease. European Journal of Gastroenterology \& Hepatology 2003;15(9):945-50.

39. West J, Card TR. Reduced mortality rates following elective percutaneous liver biopsies. Gastroenterology 2010;139(4):1230-7.

40. Cadranel J-F, Rufat $P$, Degos F. Practices of liver biopsy in France: results of a prospective nationwide survey. Hepatology 2000;32(3):47781.
41. Standish R, Cholongitas E, Dhillon A, Burroughs A, Dhillon A. An appraisal of the histopathological assessment of liver fibrosis. Gut 2006;55(4):569-78.

42. Bedossa $P$, Dargère $D$, Paradis $V$. Sampling variability of liver fibrosis in chronic hepatitis C. Hepatology 2003;38(6):1449-57.

43. Tsochatzis EA, Germani G, Dhillon AP, Burroughs AK. Noninvasive assessment of liver fibrosis: the clinical context and question are important. Hepatology 2011;54(6): 54:2276.

44. Castera L, Chan HL, Arrese M, et al. EASL-ALEH Clinical Practice Guidelines: Non-invasive tests for evaluation of liver disease severity and prognosis. Journal of Hepatology 2015;63(1):237-64.

45. Bedossa P, Carrat F. Liver biopsy: the best, not the gold standard. Journal of Hepatology 2009;50(1):1-3.

46. Papastergiou V, Tsochatzis E, Burroughs AK. Non-invasive assessment of liver fibrosis. Annals of Gastroenterology 2012;25(3):218. 